\title{
Outreach in Diverse Communities: A Conversation with James Rojas
}

\author{
Kelly Main \\ PhD; assistant professor, CRP Department.
}

\begin{abstract}
Public participation is essential for planning and urban design in ensuring social and cultural equity in a democratic process of governance. The CRP Department hosted James Rojas, a planner and expert in community and particularly Latino engagement, for a talk and a workshop exercise with students. Faculty Kelly Main, his host and deeply involved with the same issues, interviewed Mr. Rojas for FOCUS.
\end{abstract}

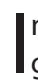

n 2007, James Rojas, an urban planner working for Los Angeles' Metropolitan Transportation Authority, independently developed a new method of community outreach designed to engage communities not typically heard as part of the urban planning process. Since then Mr. Rojas has facilitated over 200 interactive workshops and created over 43 interactive urban dioramas across the world, collaborating with municipalities, non-profits, educational institutions, museums, and galleries to educate the public on urban planning. In April 2012, Mr. Rojas conducted a workshop with Cal Poly students and members of the Central Coast chapter of the APA to introduce them to his outreach technique. Following the workshop, we invited Mr. Rojas to be interviewed for FOCUS.

Main: How would you briefly describe your outreach process?

Rojas: I start the process by asking the participants a simple question that pertains to the built environment. It might be "How would you design your ideal city?", or "How would you re-create your favorite childhood place?", or "How would you improve mobility in your community?"

Participants have no constraints, which helps maximize their creativity. There is no discussion, no scale, maps, pictures, no terms to learn, and no wrong or right answers; the only requirement is that everybody creates a three dimensional model.

In the next step participants are given twenty minutes to selfreflect and build their solutions. Participants are given a blank piece of paper and a medley of recycled objects to choose from. The thousands of small colorful, vibrant, tactile, objects trigger the participant's emotional connections to the built environment. Participants connect and synthesize how they experience urban space by seeking and touching these objects. By using nondescript objects, participants are forced to be creative: Green yarn becomes grass, blue poker chips become the ocean, and hair rollers become apartments or office buildings. Using their hands and minds, they create and re-imagine their idea of an ideal city, street, public space, or building.
After the twenty minutes are up the participants have one minute to explain their ideas through the model to the group. This forces everyone to see each other's creation and listen to each other. As a facilitator, I ask people to state their name and tell us about their idea/plan. One minute keeps up the pace of the exercise. To anyone who has immigrants or children, one minute is long and they may need help explaining their models.

Since people interject their own personal experiences, memories, and random thoughts of place, both real and imagined, the explanation becomes the most interesting part of the process, as it allows for everyone to publicly bond and engage in the process. An understanding or recognition of familiarity is shared among the group.

Once the participants have completed their one-minute presentation, I quickly synthesize the information and repeat it back to the larger audience. Once that is complete, we want to celebrate the exercise and the fascinating explanations shared among the group through applause.

Main: How did you develop the process?

Rojas: Growing up I didn't have building blocks or Lego's. My grandmother gave me a shoebox filled with small objects to play with when I was 2 or 3 years old. The objects were buttons, old jewelry, bottle tops, and other things she collected from around the house. I began putting together buildings, houses, and cities with the objects.

I began collecting objects myself. As a kid my pockets were always full of stuff I found on the streets or sidewalks. I started to collect Popsicle sticks from the schoolyard. I would spend hours recreating houses and cities from the objects. Because these objects were random, I was forced to use my imagination. From this time on, every few months, even in adulthood, I would crack open the box of stuff and build a model city.

This was my introduction to city planning! It wasn't until a few years ago that I opened up an art gallery in Downtown Los An- 
geles [G727] and began collaborating with artists. I became fascinated with how artists use their imaginations to capture the landscape. I came to think about city models again. One weekend I displayed my model in the gallery. It was received well by the public. I began to rethink my city models, not as static pieces of art, but as an interactive tool to get people to react visually to the models by projecting their ideas onto them.

\section{Main: How did your models go from art to outreach?}

Rojas: As a community organizer I was always frustrated with the lack of input from Latino/as on plans, projects, and civic matters. I started to run the hour-long workshops to engage, educate, and empower Latinos in the planning and design process. Young people, immigrants, and women oftentimes don't engage in the planning process due to language barriers, lack of technical knowledge, and cultural biases. As a result, many of the projects, plans, and developments within their communities fail to meet their needs.

In November of 2007, at the request of Taking the Reins, a nonprofit organization serving adolescent girls from urban, at-risk environments in Los Angeles, I facilitated a charrette using my new method. The charrette, which lasted three hours, comprised fifteen Latina youths and architect Peter Tolkin to help them envision a future place for themselves and their horses. The exercise was a great success because the girls were able to articulate, never-before-seen spaces through the method. This exercise provided much needed input that the architect later used to design the stables.

Main: I know you have held these workshops in different forms all over the world. What were a couple of your most interesting experiences?

Rojas: I had the privilege of representing the United States at the United Nations Habitat World Urban Forum (WUF). As part of the WUF conference, there was an exhibition area where various nations, public institutions, and non-governmental organizations could set up booths to showcase their work. I created an interactive model of a Car-Free Rio de Janeiro for the booth.

Hundreds of participants from around the world visited the U.S. booth daily. Many of the conference participants were fascinated by the vibrant colors, recycled materials, and the purpose of the interactive model. Once attendees were aware that they could touch the model, many became fascinated with rearranging it. This allowed me to engage with attendees ranging from heads-of-state to casual passersby.

I also facilitated an interesting project in New York City. For the five weeks I was there, hundreds of New Yorkers were my guinea pigs. From Wall Street to the South Bronx, from children to adults, from Spanish-speaking immigrants to professionals, everyone had an opportunity to listen, learn, and inspire each other with their urban visions.
NYC was a great platform to experiment with my practice. I facilitated twelve workshops in various locations from indoor to outdoor, public to private, intimate to large audiences. These workshops allow me to push the limits on how we as planners do community engagement. All workshops were transformative for the participants and in addition provided valuable planning data for the various groups.

Main: Speaking of data, how do you record what you learn in the sessions? How do you pass it on to planners/decision-makers?

Rojas: Documentation is an important part of the process. It separates my process from an art process. Taking notes, pictures, and filming the process can achieve documentation. After participants have completed their individual task, they are asked to work together and create a group model synthesizing all their explanations into one great idea. During this phase of the exercise, the participants tend to combine models, only to realize that they must compromise, altering their ideals for the greater good of the community. The time for this is typically $15 \mathrm{~min}$ utes followed by a one-minute explanation where the various groups of participants share their grand idea with one another.

The first step is to analyze and synthesis all the data into categories depending on the mission of the workshop. What are long term or shorter solutions? What are solutions and what are experiences? What are people really telling us? For example, one person created a kite system to move around the city. What this is telling us is this person wants a creative, experiential transportation system that does not harm the environment.

Main: Can you give me an example of what has come out of a workshop?

Rojas: Recently I've been working with Professor Sandoval [of the Planning, Public Policy and Management Department] at

Figure 1: One of James Rojas's interactive model-building workshops with kids in a Los Angeles park. (photo by K. Main)

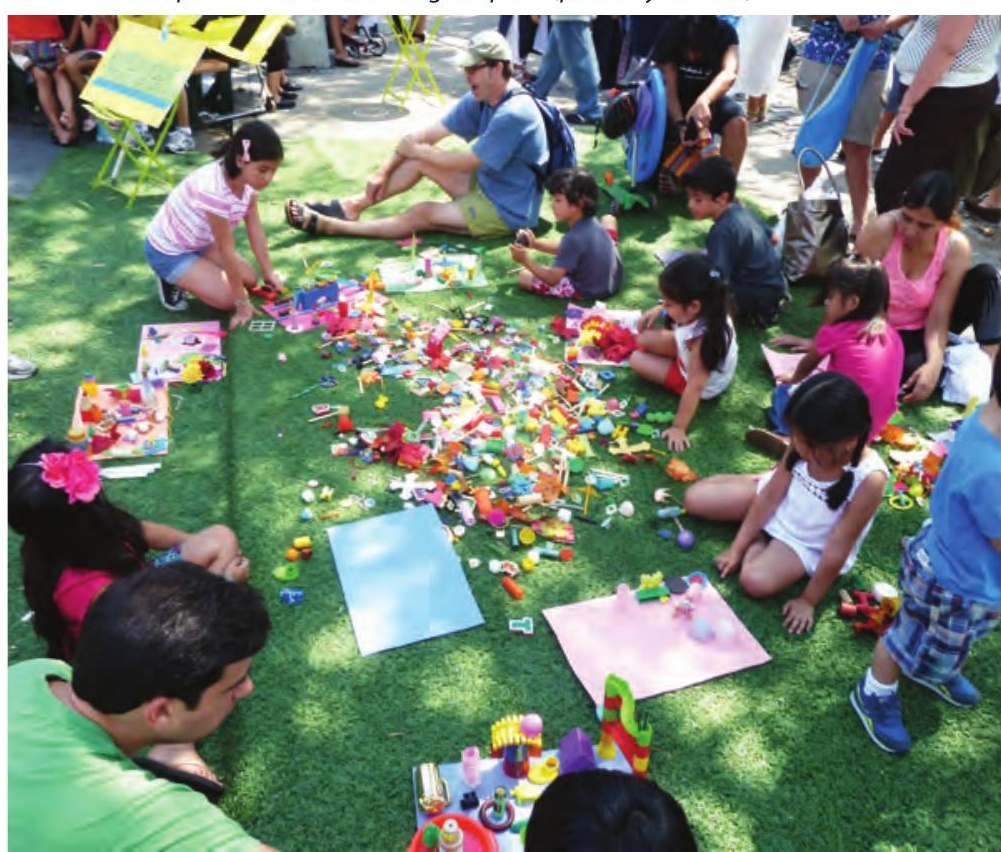




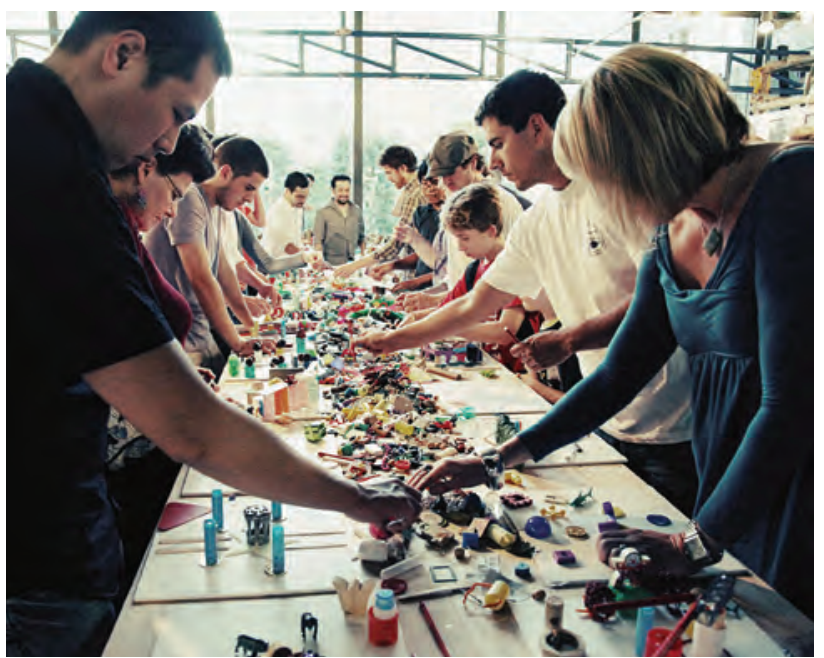

Figure 2: In the workshop Re-Imagining LA conducted by James Rojas at the Urban Land Institute 2011 conference in Los Angeles, participants built an internactive model of Wilshire Boulevard. (photo by Carla Choy, http://secretagentpr. wordpress.com/2011/10/19/the-square-uli-live/img_8185-1/

the University of Oregon as part of a HUD Sustainable Communities Grant. The point of the grant is to engage marginalized Latinos in Eugene/Springfield Oregon on urban planning issues.

We held two workshops, and the responses were overwhelming. There were ninety Latino participants whose voices are usually left out of the planning process; there were also between 15 and 20 other participants-teachers and principals at the elementary schools where the workshops took place, city staff, leaders from the University of Oregon's Sustainable Cities Initiative, and staff members of the Sightline Institute. The staff members from the Sightline Institute will be developing what we heard into community indicators.

We intentionally invited children to participate in the workshop. We wanted to allow parents to spend time with their children. We also wanted to give children a voice in the city planning process, so they could learn how community engagement can be fun and to ease the seriousness of the planning process. The community meeting was like a family gathering.

The first workshop asked a very broad question, How would you create your ideal community? The second workshop asked them to identify a specific problem in their neighborhood and to design a solution to that problem. Dozens of ideas emerged. When we were sharing with each other, people focused on three issues: security related to community; security related to food, such as access to community gardens; and access to public spaces.

\section{Main: How do you address security related to community?}

Rojas: Many people stated they wanted to feel more securethey didn't feel safe in their communities. This makes sense, as many were unauthorized immigrants. Their unease with not being a part of the greater community really came through in these workshops. For example, instead of asking for social services or planning services or saying that their housing or transportation could be improved, they spoke about wanting a better sense of belonging and the ability to enjoy public spaces. This is fascinating because we would have never thought about these issues if we kept the process top-down with only a predetermined set of options as potential concerns.

Unauthorized communities live in the shadows, away from the watchful eyes of city planners and public authorities. Many don't trust city officials, academics, or community development people who would like to understand the key issues immigrants are facing. In a situation like this, it is critical to start by learning how to reach out to one of the most marginalized and vulnerable populations and understanding their visions for creating their ideal city.

Their feedback was genuine and deep. I think our event actually contributed to their sense of community because people shared their ideas with each other rather than a city official or professional designer.

Main: So many responses to the city seem influenced by one's cultural background. Have you found responses that seem to be universal, across cultures?

Rojas: Culture, memory, and place have an impact on how people interact and understand space. However, we are all humans and share the same emotions, personal growth patterns, gender roles, and professions.

Some design elements are universal. Colors like blue symbolize water, and green symbolizes plants/parks. Forms like long flat pieces symbolize mobility, while tall things symbolize buildings. I do not use blocks because I do not want to limit people. I use lots of round objects.

Children build cities based on their interactions with the built environment. They react to the world in an unbiased way or before they are taught how to behave. They do not see streets, or buildings. They see interactions. Their emotions drive the process: how they see, touch, smell and feel the environment. I've noticed that many girls create rich landscapes of great details, while many boys create interactive activities such as football fields, skate parks, water slides, and other opportunities to engage their bodies. Both boys and girls create petting zoos. The idea of seeing and touching animals is very important to both boys and girls.

Senior citizens are the hardest group to work with. I have to be clever in developing the right question to get them to engage. The materials alone will not do it. I usually ask them to create a place for their children and grandchildren.

Main: You've done this work for quite awhile now. Are there things that still surprise you? 
Rojas: I am constantly modifying, changing up the questions, venues, and work with various clients, artists, and others. I am constantly surprised how people think about space through their experiences and memories. Some of these memories may be twenty years old or from five minutes ago.

Main: I know many of your workshops, if not most, are with community members who have almost no experience with "planning" language or processes. You've also had workshops with professional planners. Are there differences between the way planners and the communities we serve respond?

Rojas: There is a big difference between how planners, engineers, architects respond to the exercise versus the general public. The design professions tend to use the exercise as brainstorming or problem solving. I tell planners I don't want the right answer, I want YOUR answer. Because at the end of the day people are people, and they are going to respond to environment based on their emotions.

Urban planners like to control the planning process. They use abstract tools such as language, maps, numbers, pictures, policies and computer programs that dazzle. So often these processes are not interactive or engaging. This process shows planners a different communication tool.

Main: You have conducted many workshops with planning students-UCLA, USC, Cal Poly Pomona, MIT, Berkeley, Cornell, Lewis and Clark, to name just a few. You just conducted a workshop with Cal Poly, San Luis Obispo undergraduates and graduate students. What did you think of the workshop?

Rojas: Having the students recreate their ideal childhood place was a great way to get them to understand how they think about space and how we carry memories with us all the time. I was amazed by their conviction and passion for their places. It's a clear indication about childhood development. All the places were kid spaces that involved physical activity. I thought we would hear about TV shows, cartoons, and video games, but I guess these activities are passive and children get very little out of them.

Many of the students' places were about exploring nature and making sense of it. Forests, trees, vacant lots, rivers, even Yosemite were created. Many of these activities explored the inquisitive nature of children. What's under the bridge? What can we see from the roof or tree house? Also it was about imagination. We created forts, games, etc. All except for two places took place outside. Males and females had the same results. This would be a great organizing tool to create healthy communities for children by asking adults about their favorite childhood places!

Main: Where do you think your workshop fits into an outreach process that may try to engage citizens over a long period of timesay identifying issues, solutions, impediments to solutions, etc.?

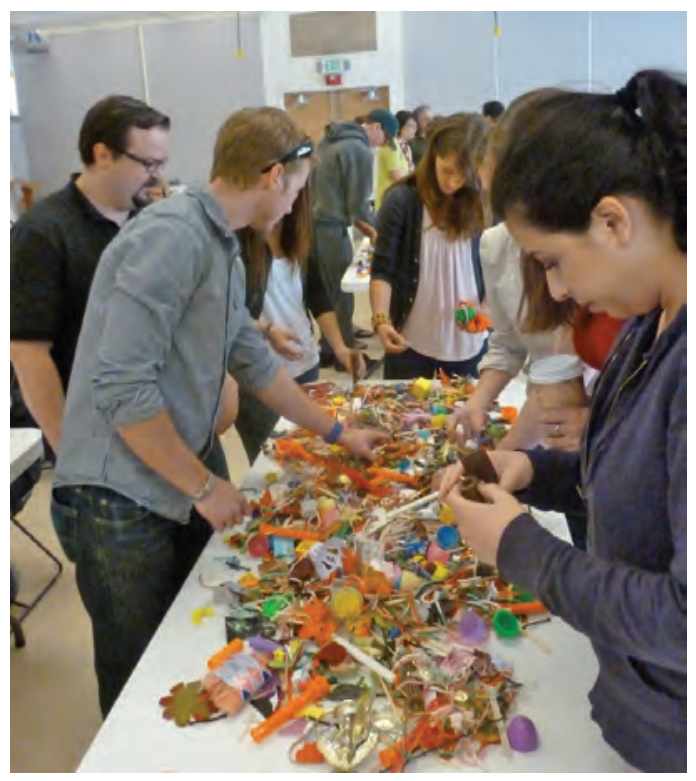

Figures 3 \& 4 : The workshop with Cal Poly students and one of the typical models that result from these exercises. (photo by K. Main)

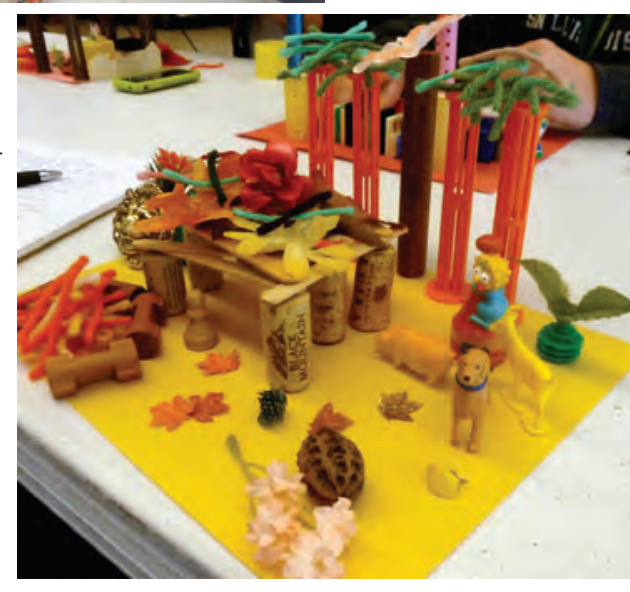

Rojas: Many of my workshops are one-time events. I see the workshops as a first step in bringing people together to share their values, and ideas. I see them as community ice breakers in helping shape and develop projects and plans. We can learn who we are, where we come from, and what we value by watching, and listening to each other.

Main: What are the limitations of this technique? In other words, what do you think you can't learn from this technique?

ROJAS: What we won't learn-we aren't going to get street widths, sidewalks, and detailed information because it's all conceptual. Also, my technique can be limited by the physical constraints of the processes such as number of people.

Main: Where do you see this work going next?

Rojas: I want to make this technique part of the urban planning process for everyone. Let everyone know that there is a different way to plan. 


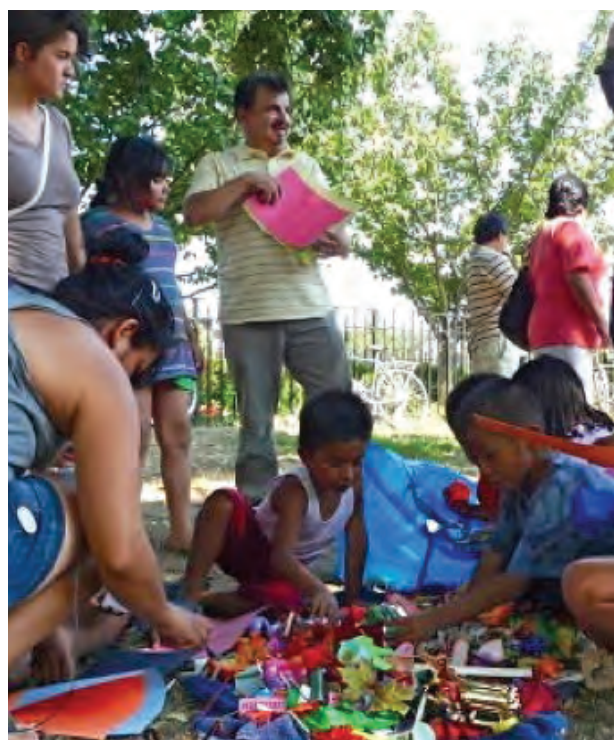

Figure 5: James Rojas during one of his workshops for kids. (photo by K. Main)

Main: You worked for the MTA for many years and were involved with a lot of outreach. If you could design an ideal process, what would it look like?

Rojas: I would develop a transportation planning process based on the experience of mobility rather than cost, destination or mode. How does it feel to be stuck in traffic, or cross a wide street, or bike on a busy street? This would improve the mobility experience and get us away from planning projects that fall short for the user.
Main: Your workshop at Cal Poly was part of a seminar on working with diverse communities. California's population is diverse and always changing. What do you think some of the biggest challenges are for outreach in diverse communities?

Rojas: My workshops thrive on diversity. The more diverse the audience the more we will learn from each other. One of the biggest challenges is how do we create an equal playing field for diverse audiences-where everyone can participate.

Main: Your life and career has had a pretty interesting trajectory. What keeps you at this? What's next?

Rojas: I like to go into cities and shake up the planning process, make planning a spectacle.

I've facilitated well over two hundred workshops through collaborations with artists, community-based organizations, teachers, curators, architects and urban planners. These workshops have been out on the street, on sidewalks, in vacant lots, museums and art galleries, as well as in a horse stable and a laundromat. I'm encouraged by the creativity and ingenuity of participants and their optimism about community change. I'm hopeful about the interest urban planners are taking in this process as a means for informing their plans and policies.

Ultimately, my goal is to effect systemic change in the planning process. I'd like to empower people, especially from economically disenfranchised and marginalized neighborhoods, to articulate and assert their vision for community improvement.

Main: What advice would you give our students just beginning their careers?

Rojas: Learn to understand your feelings! Find what makes you happy, and try everything once.
James Rojas is an urban planner, community activist, and artist. He is one of the few nationally recognized urban planners to examine U.S. Latino cultural influences on urban design. He holds a Master of City Planning degree and a Master of Science of Architecture Studies degree from the Massachusetts Institute of Technology. His influential Masters thesis on the Latino built environment-- "The Enacted Environment: The Creation of Place by Mexican/Mexican Americans in East Los Angeles"--has been widely cited in both trade and academic journals.

Mr. Rojas founded the Latino Urban Forum (LUF), a volunteer advocacy group, dedicated to understanding and improving the built environment of Los Angeles' Latino communities. LUF has recruited urban planners, architects, artists, and public administrators to lend their knowledge and influence to innovate and address the issues of the underserved, and often underprivileged, Latino communities of Los Angeles. Most recently, he helped develop the urban planning pilot program for high school students at Esteban Torres High School in East Los Angeles-The East Los Angeles Renaissance Academy of Urban Planning and Design.

His visit to Cal Poly was funded by the City and Regional Planning Department and the Central Coast Session - California Chapter of the American Planning Association. 